\title{
Saccular Aneurysm of the Aortic Arch
}

\section{Arkus Aortanın Sakküler Anevrizması}

\author{
Yusuf Karavelioğlu1, Emrah Ereren², Adnan Yalçınkaya², Adem İlkay Diken² \\ ${ }^{1}$ Hitit University Faculty of Medicine, Department of Cardiology, Çorum, Turkey \\ ${ }^{2}$ Hitit University Faculty of Medicine, Çorum Training and Research Hospital, Department of Cardiovascular Surgery, \\ Çorum, Turkey
}

A 65 year old woman was admitted to our hospital with dyspne. She had a medical history of hypertension. Her blood presure was $156 / 107 \mathrm{mmHg}$ under medication. Physical examination and routine blood tests were normal. The electrocardiogram showed sinus rhythm. Standard anteroposterior chest radiography (Figure 1A) showed a widened mediastinum so a thoracic aortic aneurysm (TAA) was suspected. Transthoracic echocardiography showed normal left ventricular systolic function and also a $36 \times 33 \mathrm{~mm}$ saccular aortic aneurysm with intraluminal thrombus which had extended to the lesser curvature of aorta with a narrow neck $(11 \mathrm{~mm})$ was seen from the suprasternal view (Figure 1B). For a more accurate assessment, we performed computed tomography angiogram of the thoracic aorta. It demonstrated that a saccular aneurysm of the mid inner curvature of aortic arch with some thrombotic material inside the aneurysm (Figures 1C, 1D). The rest of the aorta was not dilated. She had no history of severe chest or back pain, hoarseness and trauma. The patient and her family were informed about the recommended surgical and endovascular repair options if needed. The patient was initially managed conservatively with aggressive antihypertensive therapy.

Key Words: Aortic arch; aneurysm

Anahtar Kelimeler: Arkus aorta; anevrizma

\section{CONFLICT of INTEREST}

The authors reported no conflict of interest related to this article.

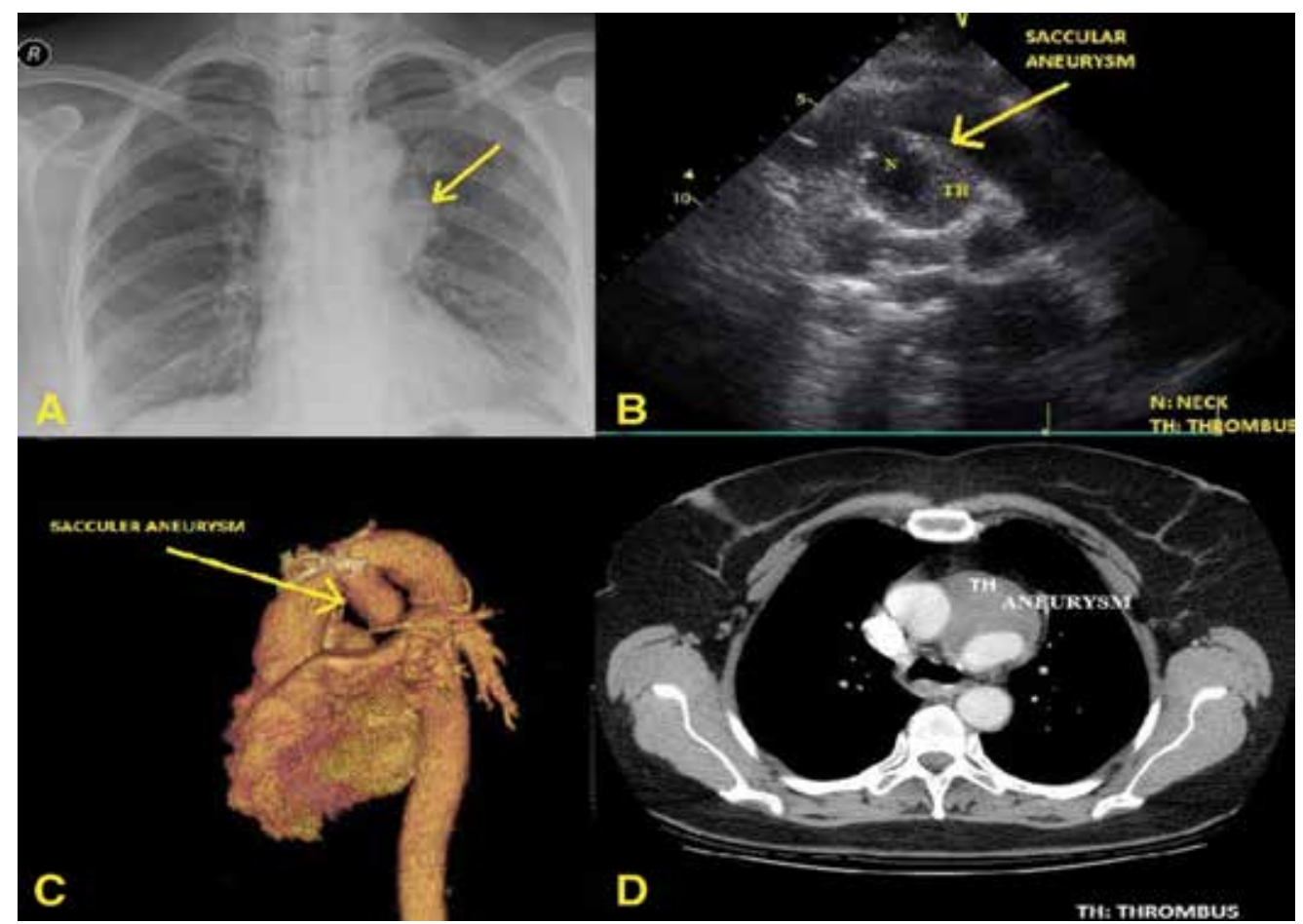

Figure 1. A- Standard anteroposterior chest radiography showed a widened mediastinum. B- 36x33 mm saccular aortic aneurysm with intraluminal thrombus which had extended to the lesser curvature of aorta with a narrow neck $(11 \mathrm{~mm})$ from the suprasternal echocardiographic view. $\mathbf{C}$ and D- Computed tomography angiograms of the thoracic aorta demonstrated that a saccular aneurysm of the mid inner curvature of aortic arch with some thrombotic material inside the aneurysm.

\section{Correspondence Yusuf Karavelioğlu \\ E-mail: drcomtr@gmail.com Submitted: 28.02 .2013 Accepted : 15.03.2013}

@Copyright 2014 by Koşuyolu Heart Journal - Available on-line at www.kosuyolukalpdergisi.com 